\title{
Your Teammate Just Sent You a New Message! The Effects of Using Telegram on Individual Acquisition of Teamwork Competence
}

\author{
Miguel Á. Conde ${ }^{* *}$, Francisco J. Rodríguez-Sedano, Ángel Hernández-García², Alexis Gutiérrez- \\ Fernández ${ }^{1}$, Ángel M. Guerrero-Higueras ${ }^{1}$
}

${ }^{1}$ Universidad de León, León (Spain)

${ }^{2}$ Universidad Politécnica de Madrid, Madrid (Spain)

Received 25 March 2021 | Accepted 26 April 2021 | Published 18 May 2021

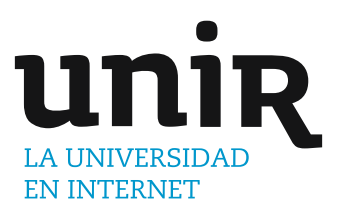

\section{ABSTRACT}

\section{KEYWORDS}

Students' acquisition of teamwork competence has become a priority for educational institutions. The development of teamwork competence in education generally relies in project-based learning methodologies and challenges. The assessment of teamwork in project-based learning involves, among others, assessing students' participation and the interactions between team members. Project-based learning can easily be handled in small-size courses, but course management and teamwork assessment become a burdensome task for instructors as the size of the class increases. Additionally, when project-based learning happens in a virtual space, such as online learning, interactions occur in a less natural way. This study explores the use of instant messaging apps (more precisely, the use of Telegram) as team communication space in project-based learning, using a learning analytics tool to extract and analyze student interactions. Further, the study compares student interactions (e.g., number of messages exchanged) and individual teamwork competence acquisition between traditional asynchronous (e.g., LMS message boards) and synchronous instant messaging communication environments. The results show a preference of students for IM tools and increased participation in the course. However, the analysis does not find significant improvement in the acquisition of individual teamwork competence.

Instant Messaging, Learning Analytics, Students Interaction, Telegram, Teamwork.

\section{INTRODUCTION}

$\mathrm{P}$ REPARING students to be successful workers or entrepreneurs is one of the main goals of educational institutions. For success to happen, students need to acquire competences that are demanded by the labor market to increase their employability and performance. However, this is easier said than done, as it requires that: 1) companies and educational institutions match learning curricula and business requirements; and 2) educational institutions use the adequate tools that facilitate competence acquisition and assessment [1]. This study addresses both issues. The first one, by exploring the application of a methodology to facilitate students the acquisition of Teamwork Competence (TWC) in educational contexts. The second, by exploring the application of a Learning Analytics tool to facilitate assessment of TWC.

The acquisition of TWC has multiple benefits for students' learning and development [2], [3] and is highly demanded by companies [1]. Different methodologies may facilitate its acquisition; most of them require that students work together in groups to develop a project or solve some problem or challenge. These methodologies share a common hurdle: while assessing the final result of a group (e.g., the project delivered) is easy and quite straightforward, it is also necessary to assess the work of each team member [4]. Strategies to address individual assessment build on the students' learning

* Corresponding author.

E-mail address: mcong@unileon.es shreds of evidence, be it based on objective observation or subjective perception. The basic types of TWC assessment techniques include the following [5]: 1) simulating events in complex scenarios [6], [7], which are generally used in courses with low number of students; 2) measuring the individual development of TWC based on different scales upon observation of students' work routines and behaviors, [8], [9]; 3) assessing performance of peers and self-assessment [10][12]; 4) analyzing objective data obtained from partial results and students' interactions in digital spaces [13], [14]. All these techniques have advantages and disadvantages; for example, the former two are based on observation and limited by the number of students; the third one introduces an important factor of subjectivity and the last one demands a great amount of time and effort from teachers. In addition, these methodologies often require face-to-face activities, and thus may prove too complex in scenarios such as the remote emergency teaching caused by the COVID19 outbreak [15], [16].

This study focuses on the fourth type of techniques (based on analysis of objective data) but aims to overcome the limitations associated with this kind of approach. To do so, we apply a learning analytics tool that facilitates assessment of TWC based on data trails from students' interactions with their teammates in online spaces, irrespective of face-to-face or distance learning.

Prior research on this topic analyzes student interactions in LMS message boards [13], [14]; this information, combined with assessment rubrics applied to partial and final results, helps assess the individual acquisition of TWC [4]. One relevant finding from those research studies is that students are not comfortable with using message boards for interaction with their peers because they consider 
that asynchronous communication is far from the real way in which they usually interact in non-educational contexts. A potential solution to this problem is to move the interaction space to Instant Messaging (IM) tools and applications, which then leads to the development of learning analytics solutions tailored to the characteristics and data structures of these applications.

IM applications have been widely adopted by the general population, but are particularly popular among younger generations. IM enables communication across multiple devices and facilitates synchronous interaction between peers, allowing for different types of messages and data formats (e.g., text, photos, video, voice, etc.) [17]. Younger users favor IM applications over other communication channels, such as phone calls [18], [19]. Additionally, most IM applications do not entail monetary costs and are available for download and use in almost every kind of mobile and non-mobile devices. Currently, the most popular and widely adopted IM application is WhatsApp [20].

Recent studies explored the use of learning analytics tools adapted to the characteristics of WhatsApp [21], [22], but their implementation requires additional data parsing to ensure anonymity, and therefore the collaboration of students and teachers because the phone number must be shared among group members. Other IM tools, such as Telegram, do not have this requirement, and thus may be more suitable to foster collaboration. Telegram offers a free open-source platform without ads, a clean interface and some extra security layers [23]. Further, it incorporates a bot system that facilitates collection and processing of messages without linking them to mobile phone numbers, using internal IDs instead.

This study analyzes the results from the combined use of Telegram and a learning analytics tool for data extraction and processing. More specifically, the research examines collaborative learning settings in two different courses of a Computer Science Degree at the University of León. This examination involves observing student engagement and interactions in Telegram groups and analyzing their relationship with the individual acquisition of TWC. We also compare the results with those of previous cohorts. This study extends [24], which described the learning analytics tool used to collect data in this research and was presented at the TEEM conference 2020. A qualitative assessment of the method based on the feedback received from students complements the quantitative analysis.

The structure of this document is as follows: Section II describes the materials and methods used on the study; Section III presents the results of the analysis; Section IV discusses the main findings and compares them with those from previous research; finally, Section V draws the main conclusions of the study.

\section{MATERIALS AND METHODS}

\section{A. Materials}

Validating a learning analytics tool entails its application in an educational context. In this study, we analyze data from two different Computer Science courses (Operating Systems and Computer Animation) at the bachelor's degree in Computer Science across two different academic years.

- Operating Systems (OS) is a second-year mandatory course delivered to between 100 and 130 students that focuses on the fundamentals of Operating Systems from a practical perspective [21]. Although theoretical concepts are given as lectures, most of the contents are developed as hands-on work. The course assessment consists of the evaluation of theoretical and practical concepts through questionnaires (35 percent of the final grade) and two mandatory assignments to assess the hands-on part (65 percent of the final grade). The latter comprises two assignments: the first one is individual and accounts for 35 percent of the handson grade, whereas the second (also called final assignment) is carried out in groups and accounts for the remaining 65 percent of the hands-on grade. Students need to pass both the theoretical and hands-on parts separately to pass the course. This study focuses on the final assignment because of prior success in applying the same methodology (Comprehensive Training Model of the Teamwork Competence, CTMTC; CTMTC is explained in more detail in subsection II.C.2) in project-based learning in the past [25]. The data collected correspond to the 2018-2019 (face-to-face course using Moodle message boards for team communication) and 20202021 (blended learning course using Telegram as communication space) academic years.

- Computer Animation (CA) is a third-year elective course where students learn general concepts about design principles and techniques, modeling and three-dimensional animation of objects [24]. The main learning objective of the course is that students experience and learn the concepts involved in all the stages of an audiovisual production project in real contexts. Course contents are divided in three blocks: introduction, animation fundamentals and animation techniques.

The assessment is based on questionnaires, applied exercises and a final project. Questionnaires (20 percent of the final grade) are used to check students' knowledge and understanding of theoretical concepts. Exercises (20 percent of the final grade) assess students' knowledge about the application of theoretical concepts. The development of an animation project (50 percent of the final grade) is carried out in teams following the CTMTC methodology; the project starts in the first classes and is worked on during the whole semester. The remaining part of the grade corresponds to class attendance. The study examines data collected from two different cohorts: 2018-2019 (face-to face course using Moodle message boards for team communication) and 2019-2020 (shifted to emergency remote teaching due to the COVID19 outbreak and using Telegram as communication tool).

\section{B. Participants}

The sample of the study is described in Table I. Each cell shows the number of students actively participating in the course over the total number of enrolled students. Students in the 2019-2020 Computer Animation and 2020-2021 Operating Systems courses were also given the choice to use message boards instead of Telegram, but all of them chose to use Telegram. Participation in the study was voluntary, and participating students had to explicitly accept and sign a consent form, by which they allowed instructors and the research team to access and analyze their data (the Spanish version of the consent form may be accessed at https://forms.gle/z9dRvSiQZ1PtZkL97). For research purposes, data is anonymized. Students could cancel this agreement at any given moment. Participants were also informed that there were not risks associated with the study, nor any payment due for participation.

From Table I, the number of students in OS doubles the number of students participating in CA, which owes to the mandatory nature of OS and the difference in the year they are taught (OS in second year and $\mathrm{CA}$ in third year).

TABLE I. Student Distribution By Course And Cohort

\begin{tabular}{cccc}
\hline Course & $\mathbf{2 0 1 8 / 1 9}$ & $\mathbf{2 0 1 9 / 2 0}$ & $\mathbf{2 0 2 0 / 2 1}$ \\
\hline OS & $92 / 107$ & & $105 / 111$ \\
CA & $44 / 52$ & $42 / 56$ & \\
\hline
\end{tabular}




\section{Applied Methods}

This sub-section describes the research methods of the study, the data collection process and a detailed explanation of the methodology followed in the courses (CTMTC), as well as particular aspects of its application in each of the courses.

\section{Methods}

The research uses a mixed-methods approach [26], combining quantitative and qualitative analysis. The quantitative analysis compares the number of messages and individual TWC acquisition [21] between academic years across courses (which used different tools for team communication purposes) and analyzes the relationship between messages exchanged and individual TWC acquisition. The analysis involves two-sample location tests to find differences between cohorts in both groups, and regression analysis to test for association between messages and individual TWC acquisition.

The qualitative data was gathered from open questionnaires with similar questions about both the methodology (CTMTC) and the digital spaces used for communication. Two questionnaires were delivered: one for courses using message boards (https://forms. gle/6oFeYxEW6HR5Lohv9) and a different one with specific questions for the instant messaging tool (https://forms.gle/51XMURZbEgCAetdd7).

\section{Course Methodology}

\section{a) CTMTC}

CTMTC is a methodology designed to develop TWC. CTMTC includes different sequential stages (storming, norming, performing, delivery and documentation), adapted from the project management area as defined by the International Project Management Association (IPMA) [27]. In CTMTC, students develop a project or complex learning activity following sequential phases and working as a team. To complete the different stages, students must make use of different technologies, such as wikis (where they publish their partial results), message boards (where they hold discussions about the project), cloud storage directories (where they upload the deliverables), etc. [13], [28]. The methodology allows for flexibility, as the digital tools may be adapted to different settings [4], [25], [28]-[32]. Using digital tools makes it also possible for instructors to track and analyze students' interactions; for example, instructors may revise the partial results published in the wiki at each phase, or go over what students post to the message boards, the documents they upload to the cloud or publish in a repository, the number of commits in a version control system, etc. These interactions facilitate observation of each team member's participation in every activity and, based on that information and the final work delivered, assessment of the individual acquisition of TWC by each student. However, accessing and analyzing that information is often burdensome, which is why the support of learning analytics tools (such as the one used in this study) become necessary [33], [34].

\section{b) CTMTC Application in Operating Systems}

CTMTC has been applied to the same assignment (final assignment, total weight of 42.25 percent of the total grade) in both cohorts of the operating systems course. In the 2018-2019 academic year and previous editions of the course, assignation of students to teams was open and free (i.e., students freely choose their teammates), and teams had between three and four members. Each team had to appoint a team coordinator, establish the team's norms and complete the different stages of the CTMTC. Students published the partial results in a Moodle Wiki and interacted with the rest of team members in Moodle message boards. They could also share and publish their results in other virtual repositories, such as Google Drive, Dropbox or GitHub. The rubric described in [32] was used for the assessment of the learning evidence and individual TWC acquisition.
In the 2020-2021 academic year, a different strategy was adopted. While the phases and team assignment did not change, the interaction between team members unfolded in the Telegram IM app. This change had an impact on the rubric, which was no longer applicable because Telegram does not provide information about whether a message is read by a specific student; in addition, the notion of short and long messages is different in IM Tools and message boards. Therefore, a different rubric tailored to the new discussion space [21] was used. Despite this change, both rubrics are similar in that they observe the partial results in the same way.

\section{c) CTMTC Application in Computer Animation}

The application of CTMTC in the computer animation course focused on the course project, with a weight of 50 percent of the final grade. In the 2018/2019 academic year, the project was developed in teams of between 8 and 9 members, and assignment of students to groups was decided by the instructors. Students published the partial results in Moodle wikis and used message boards to interact and discuss. As in the operating systems course, students made use of cloud-based software (e.g., Google Drive or Dropbox) to share and publish the project's intermediate documents and deliverables. The learning analytics tool analyzed interaction logs from the message boards to help understand and assess students' interactions.

In 2019-2020 academic year, upon realizing that the quality of the final outcomes of the project were subpar, the instructors made some changes, reducing the number of team members to four, and allowing students to freely choose their teammates. Additionally, Telegram was used instead of message boards as interaction space. As in the case of the operating systems course, the original rubric designed for message boards required adaptation to analyze Telegram interactions.

\section{RESULTS}

\section{A. Quantitative Results}

As mentioned above, the analysis compares number of messages sent by students and individual acquisition of TWC. Table II summarizes the main descriptive statistics.

TABLE II. Descriptive Statistics

\begin{tabular}{cccccc}
\hline Course & $\mathbf{N}$ & $\begin{array}{c}\text { Messages } \\
\text { (mean) }\end{array}$ & $\begin{array}{c}\text { Messages } \\
\text { (SD) }\end{array}$ & $\begin{array}{c}\text { Indiv. } \\
\text { TWC } \\
\text { (mean) }\end{array}$ & $\begin{array}{c}\text { Indiv. } \\
\text { TWC (SD) }\end{array}$ \\
\hline $\begin{array}{c}\text { OS } \\
(\mathbf{1 8 - 1 9 )}\end{array}$ & 92 & 29.88 & 21.58 & 6.95 & 1.58 \\
$\begin{array}{c}\text { OS } \\
(\mathbf{2 0 - 2 1 )}\end{array}$ & 105 & 167.38 & 169.70 & 7.21 & 2.13 \\
$\begin{array}{c}\text { CA } \\
(\mathbf{1 8 - 1 9 )}\end{array}$ & 44 & 73.45 & 54.56 & 4.98 & 2.80 \\
$\begin{array}{c}\text { CA } \\
(\mathbf{1 9 - 2 0})\end{array}$ & 42 & 160.02 & 163.22 & 5.83 & 3.19 \\
\hline
\end{tabular}

Fig. 1 shows the interaction plots comparing the results of the analysis of both cohorts. From Fig. 1, there is an overall improvement in individual TWC acquisition and a high increase in the average number of messages posted by students.

To test the significance of the differences, the analysis uses the ggbetweenstats function of the ggstatsplot package in $\mathrm{R}$ [35]. Ggstatsplot combines statistical details and graphical output, making data exploration simpler and faster. Prior to the analysis, we tested for normality of the two variables under study (messages exchanged by each student and individual TWC acquisition) using the ShapiroWilk test. Because normality could not be confirmed in the case of 


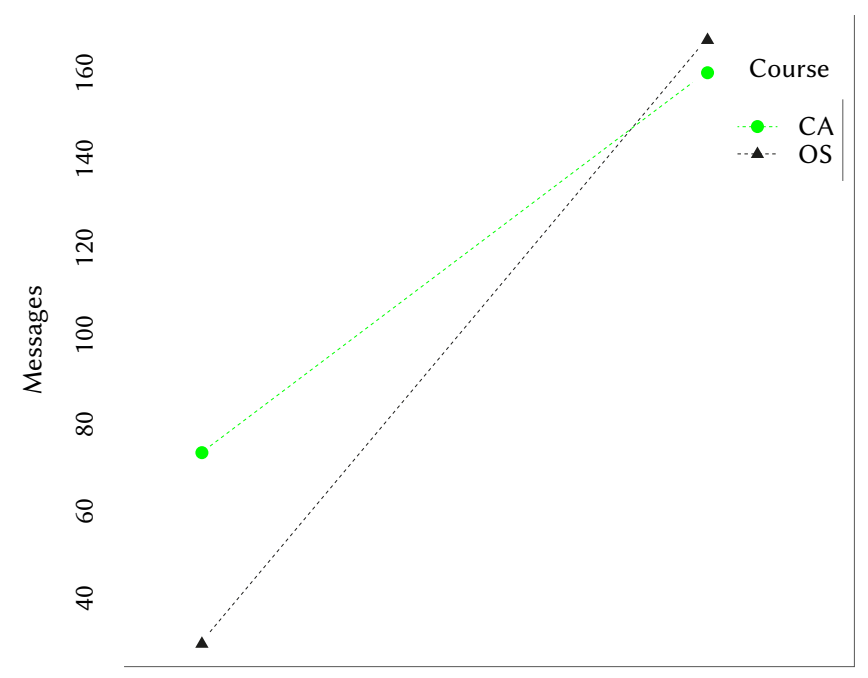

Message boards
Telegram

Message tool

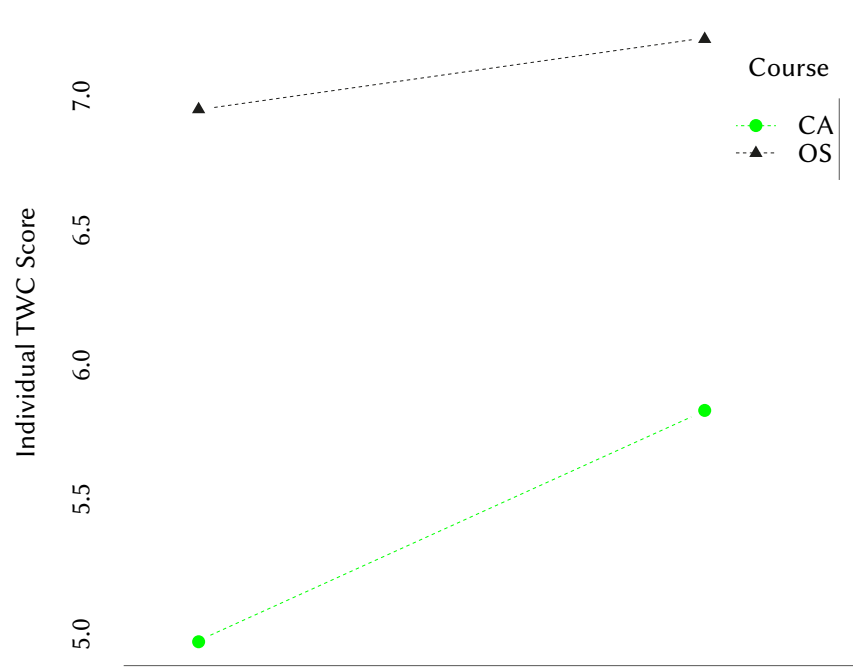

Message boards
Telegram

Message tool

Fig 1. Interaction plots of number of messages (left) and Individual TWC scores (right) across both cohorts in the two courses (CA: Computer Animation; OS: Operating Systems).

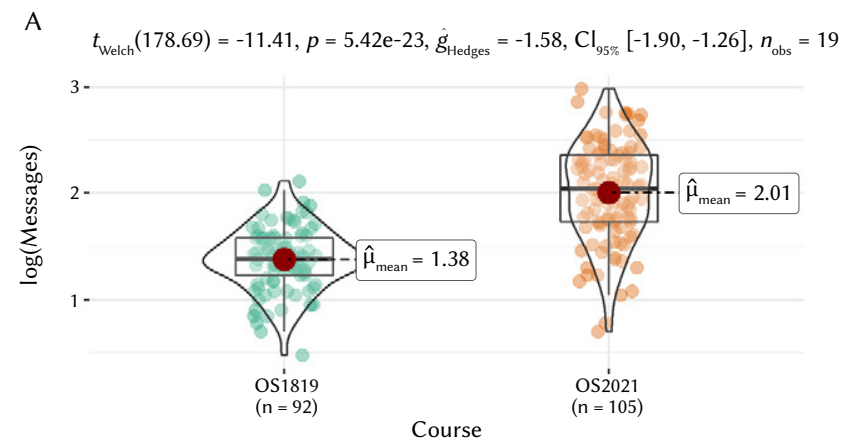

$\log _{\mathrm{e}}\left(\mathrm{BF}_{01}\right)=-44.32, \hat{\delta}_{\text {difference }}^{\text {posterior }}=0.62, \mathrm{Cl}_{95 \%}^{\mathrm{HDI}}[0.51,0.73], r_{\text {Cauchy }}^{\mathrm{JzS}}=0.71$

C

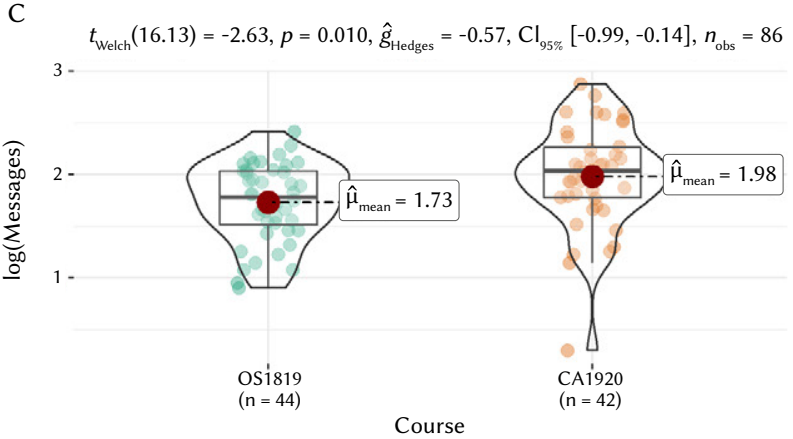

$\log _{\mathrm{e}}\left(\mathrm{BF}_{01}\right)=-1.51, \hat{\delta}_{\text {difference }}^{\text {postrio }}=0.23, \mathrm{Cl}_{95 \%}^{\mathrm{HDl}}[0.05,0.42], r_{\text {Cauchy }}^{\mathrm{JZS}}=0.71$
B

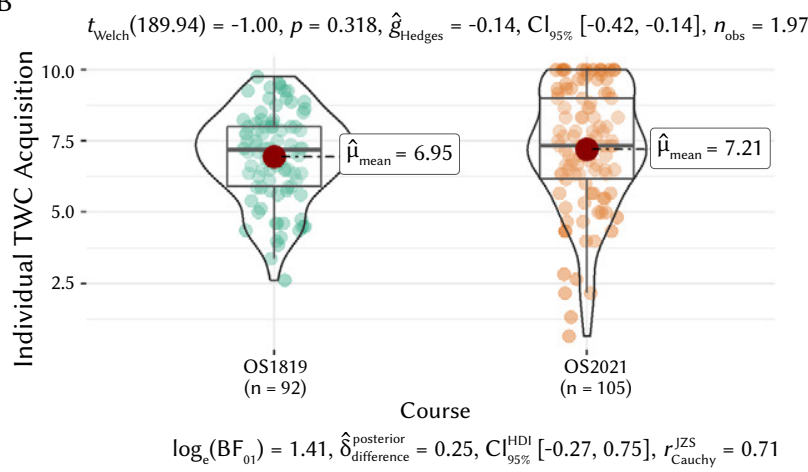

$\mathrm{D}$

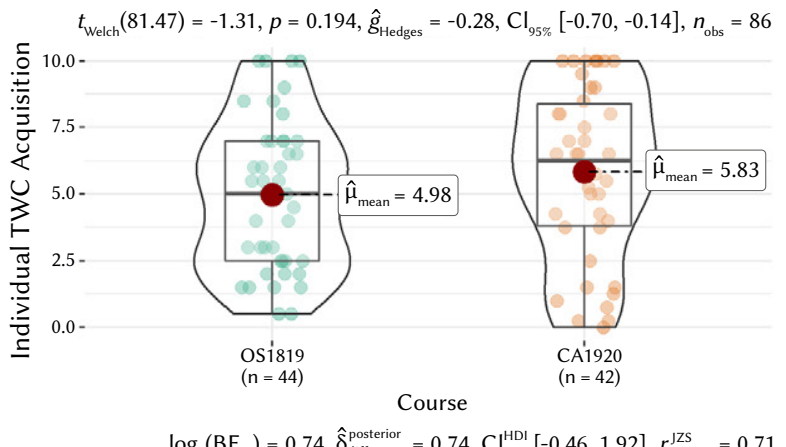

Fig 2. Results of the two samples-location tests of $\log ($ Messages) (A, C) and Individual TWC acquisition (B, D) across cohorts of the two courses.

number of messages $(\mathrm{p}<0.05)$, it was necessary to apply a logarithmic transformation of the variable, which then met the normality assumptions. Fig. 2 shows the results of the two-samples location test.

From Fig. 2, the results confirm the significant increase in the number of messages, but the analysis shows no significant increase in individual TWC acquisition.

We then use linear regression to compare the relationship between individual TWC acquisition and messages in each cohort. The analysis includes the interaction effect due to the introduction of Telegram. Table III summarizes the results of the analysis.

From Table III, there is a significant positive relationship between messages and individual TWC acquisition. Further, the results indicate that the influence of number of messages on individual TWC acquisition (i.e., the interaction term) is similar across both cohorts in the two courses. 
TABLE III. Results of the Multiple Linear Regression Analysis

\begin{tabular}{lccc}
\hline & Estimate & Std. Error & p-value \\
\hline OS (Adj. $\mathbf{R}^{2}$ : 0.78) & & & \\
\hline (Intercept) & 0.65 & 0.44 & 0.14 \\
Messages & 4.57 & 0.31 & 0.00 \\
Telegram & -1.59 & 0.58 & 0.01 \\
Messages ${ }^{\star}$ Telegram & -0.51 & 0.36 & 0.16 \\
\hline CA (Adj. $\left.\mathbf{R}^{2} \mathbf{0} \mathbf{0 . 6 3}\right)$ & & & \\
\hline (Intercept) & 5.62 & 1.30 & 0.00 \\
Messages & 6.12 & 0.74 & 0.00 \\
Telegram & 1.46 & 1.74 & 0.40 \\
Messages ${ }^{\star}$ Telegram & 1.09 & 0.93 & 0.25 \\
\hline
\end{tabular}

\section{B. Qualitative Results}

The qualitative analysis explores students' answers to open questions. Participation was voluntary, and the total number of replies is shown in Table IV. Questions about CTMTC and different software tools other than those relative to interaction and discussion spaces were the same across all courses; questions about Telegram were asked only to students in cohorts that used this IM application. We group the answers by proximity criterion for Q1 (advantages of CTMTC), Q2 (drawbacks of CTMTC), Q3 (additional tools students used to complete the project) and Q4 (advantages of Telegram when compared to asynchronous tools such as message boards). The results are presented in a matrix style, as suggested by [36].

TABLE IV. Number of Replies to the Questionnaire by Course and Year

\begin{tabular}{lccc}
\hline Course & $\mathbf{2 0 1 8 / 1 9}$ & $\mathbf{2 0 1 9 / 2 0}$ & $\mathbf{2 0 2 0 / 2 1}$ \\
\hline OS & 72 & & 90 \\
CA & 31 & 22 & \\
\hline
\end{tabular}

Table V shows the responses from 40 students (the 10 first answers from each course). In addition, it must be noted that 96.7 percent of the students highlighted the ease of use of the Telegram bot.

\section{DISCUSSION}

The results from this study are in line with previous research. From the quantitative analysis, we can observe similarities across the courses. For instance, the use of Telegram causes an overall significant increase in the number of messages posted by students; the average number of Telegram messages in the computer animation course approximately doubles that of message boards, and in the operating systems course this number is more than five times higher. There are two explanations to this finding:

1. The messages sent through IM apps are generally shorter than those posted to message boards. Therefore, communicating the same content generally entails sending more messages. For reference, a message sent through WhatsApp may be considered long when the number of characters is greater than 40 [37], [38] whereas in message boards long messages contain 150 characters or more [28].

2. Students feel more comfortable with tools they use in their everyday life, provide instant update notifications and are accessible in different devices, particularly mobile devices [39], and therefore tend to use them more often. This explanation is supported by the students' answers to the open question about the use of Telegram.
In both courses and both cohorts of each course, the results show that the relationship between the number of messages and individual TWC acquisition is positive and significant. This result confirms the findings of [4], [40] and shows that engagement and motivation are related to improvement in individual acquisition of TWC [4] and could be also related to an improvement in academic performance [41].

Despite the 3.7 and 17.0 percent increase in individual TWC acquisition in the OS and CA courses, respectively, the analysis cannot confirm whether the use of Telegram leads to significant improvement in TWC acquisition when compared to the use of message boards. Even though further research is necessary to shed light on this finding, we may anticipate some potential causes of these finding, which can be summarized in four explanations:

1. Issues pertaining to the use of mobile devices and instant messaging apps for educational purposes. Although prior research highlights the benefits associated with the use of these tools in learning contexts, especially regarding student interaction [42][47], they are also known to cause distraction from the task at hand [48], [49]. It is possible that this effect is also present in the courses under analysis in this study: the results reflect an increase in interactions between team members, but the introduction of Telegram might have led to students not paying the required attention to the group activity. Further analysis investigating the number of multimedia messages, emojis exchanged, as well as discourse analysis using natural language processing could help assess whether interactions were focused on the team activity.

2. Despite the growing use of Telegram, its acceptance is still far from that of other widespread applications, such as WhatsApp [20]. Therefore, students might feel that they are being forced into using Telegram when there is still a practical gap in whether it has already been incorporated to their everyday life. Consequently, its effectiveness may be reduced. Further research is needed to compare the effectiveness of both applications, given their differences in user base and features: user ID, group management, bots, API access, pools, emojis, keyboards or backup processes [50]-[52].

3. Being familiar and proficient with the use of an application for personal use in everyday life does not equate to being able to take advantage of its potential in educational contexts; in other words, being a digital native does not necessarily translate to being a digital learner [53]. As a consequence, proficiency in the use of a tool in a private context may not be associated with an improvement in individual TWC acquisition when using the tool in an educational setting. In addition, even though message exchanges play an important role in individual TWC acquisition, there are other relevant variables influencing individual TWC acquisition, such as other evidence of collaboration activity and leadership [21].

4. Aspects related to COVID19. Prior research suggests that student academic achievement improved under emergency remote teaching during the lockdown period [54], [55]. However, scholarly research has yet to address the effect of the pandemic on team dynamics in project-based learning, which might be potentially hindering TWC development. The computer animation course in the 20192020 academic year was given online due to lockdown, and the operating systems course in the 2020-2021 academic year followed a hybrid approach, with half of the groups alternating face-to-face and online sessions every other week. Remote learning might hamper effective teamwork when this skill is yet to be developed by students, and changes in the learning delivery method may reduce both the effectiveness of project-based learning and student motivation, making it more difficult to adequately follow the course. Notably, the change from face-to-face instruction 
TABLE V. Selection of Responses to the Open Questions, Classified in CATEgories

OS1-XX: Operating Systems, 2018-2019 Academic Year; OS2-XX: Operating Systems: 2020-2021 Academic Year

CA1-XX: Computer Animation, 2018-2019 Academic Year; CA2-XX: Computer Animation: 2019-2020 Academic Year

\begin{tabular}{|c|c|c|c|c|}
\hline Course & Q1 (CTMTC Advantages) & Q2 (CTMTC Drawbacks) & Q3 (Other tools) & Telegram \\
\hline CA1-01 & Working together and planning the tasks & Some people do not know to work in teams & - & - \\
\hline CA1-02 & Distributing workload & Peers' responsibility & Version control systems & - \\
\hline CA1-03 & Learning in groups and from others & Group size & WhatsApp, Skype, Telegram & - \\
\hline CA1-04 & All tasks planned and organized & Initial effort & - & - \\
\hline CA1-05 & Distributing workload & Use of message boards as communication tool & Other messaging tool & - \\
\hline CA1-06 & Knowledge Sharing & Agreement with peers & - & - \\
\hline CA1-07 & Importance of coordination & Effort required by all & Other communication tools & - \\
\hline CA1-08 & Working in groups & Coordination effort & - & - \\
\hline CA1-09 & Seeing the whole work & Dependent on how your partners work & Other than message boards & - \\
\hline CA1-10 & Individual participation in teamwork & $\begin{array}{l}\text { Message boards are a bad choice for } \\
\text { communication }\end{array}$ & - & - \\
\hline CA2-01 & Learning how to work in a team & Coordination effort & - & Useful and easy to use \\
\hline CA2-02 & Working distribution & Differences in engagement among team members & - & Very straightforward \\
\hline CA2-03 & Knowing other opinions and solutions & Difficulty to reach consensus & - & Instant messages \\
\hline CA2-04 & Learning from peers & - & - & Used in my daily life \\
\hline CA2-05 & Good for planning & Following all the stages & Drive & I would prefer WhatsApp \\
\hline CA2-06 & Procedure to work in groups & - & Trello & Good for communication \\
\hline CA2-07 & Distributing responsibilities & Higher workload & Discord & Better than message boards \\
\hline CA2-08 & Addressing more complex projects as a group & Distribution of responsibility & - & Direct notifications \\
\hline CA2-09 & Finding better solutions & Effort to work as a group & Skype & Mobile use \\
\hline CA2-10 & Easier to reach a solution & Involvement and consensus & Discord & Quick to read and answer \\
\hline OS1-01 & Working as a team & Peers not completing their tasks & - & - \\
\hline OS1-02 & Addressing big projects & Documenting the progress & A better messaging tool & - \\
\hline OS1-03 & Learning how to work in a team & Difficulty to coordinate & - & - \\
\hline OS1-04 & Distributing effort & - & IM tools (e.g., WhatsApp) & - \\
\hline OS1-05 & $\begin{array}{l}\text { Structuring the work and fostering team } \\
\text { members participation }\end{array}$ & Reporting the work done & Telegram & - \\
\hline OS1-06 & Easy method that facilitates coordination & Mandatory use of message boards & - & - \\
\hline OS1-07 & Facilitating planning and report of work & Initial understanding of the methodology & WhatsApp & - \\
\hline OS1-08 & Individual assessment of team members work & Unsuited for large groups & Version control systems & - \\
\hline OS1-09 & Proper distribution of the workload & Coordination effort & - & - \\
\hline OS1-10 & $\begin{array}{l}\text { Facilitates the coordination between team } \\
\text { members }\end{array}$ & $\begin{array}{l}\text { Moodle message boards hindering natural } \\
\text { conversation }\end{array}$ & Instant messaging tools & - \\
\hline OS2-01 & Easy to apply & - & Discord & $\begin{array}{l}\text { Easy to follow with daily } \\
\text { life tools }\end{array}$ \\
\hline OS2-02 & Workload distribution & - & Discord & Better than message boards \\
\hline OS2-03 & Reporting the work done as a team & - & $\begin{array}{l}\text { Discord, WhatsApp, Notion, } \\
\text { Repl.it, GitHub }\end{array}$ & Comfortable and convenient \\
\hline OS2-04 & Coordination to work together & - & Skype & Easy to use and mobile \\
\hline OS2-05 & Structure the work applying a method & Reporting may be hard & Repl.it para, Notion Goodnotes & $\begin{array}{l}\text { Better than a message board } \\
\text { and multidevice }\end{array}$ \\
\hline OS2-06 & Assessing individual contributions & Reporting & Discord & $\begin{array}{l}\text { A common and accessible } \\
\text { tool }\end{array}$ \\
\hline OS2-07 & Working together & Describing the work done & - & Better communication \\
\hline OS2-08 & Distributing work and assessing it individually & - & Discord & $\begin{array}{l}\text { More natural and dynamic } \\
\text { communication }\end{array}$ \\
\hline OS2-09 & Work organization and tasks distribution & - & - & $\begin{array}{l}\text { Instant messages and } \\
\text { notifications }\end{array}$ \\
\hline OS2-10 & Planning the work & - & - & $\begin{array}{c}\text { Easy access to information in } \\
\text { mobile phones }\end{array}$ \\
\hline
\end{tabular}


(academic year 2018-2019) to hybrid sessions (academic year 20202021) caused a rise in student participation of the course, from an average number of students completing the final assignment of 79 percent in 2016-2017 (not considered in the study) to 88 percent in 2018-2019 and a whopping 97 percent in 2020-2021. In previous editions, students who were not participating or were reluctant to participate generally did not submit the final assignment, but in the 2020-2021 cohort almost all enrolled students submitted the final assignment. Consequently, lower quality projects that were organically filtered out in previous editions were delivered in the most recent course, potentially lowering the average final grade. In addition, other covariates related to decisions about the instructional design might be affecting the results (e.g., different group sizes and instructor-led versus free choice in group configuration) [32].

From the results of the qualitative analysis, the results are in line with findings from previous studies where CTMTC was applied, regardless of the communication tool [29], [32]. All participants mention advantages of the methodology, but one quarter of all students did not find any disadvantage in the application of the methodology. Students highlight benefits associated with project management, planning, workload distribution, reporting and assessing the individual and teamwork. All these aspects are related to teamwork behavior [12], a necessary condition for TWC acquisition.

Regarding disadvantages, 16 percent of students identify the use of message boards as a problem, 40 percent state that more effort, coordination and reporting is necessary when applying CTMTC, and the rest of students point at potential issues related to workload distribution and individual team members not being able to complete the tasks they are assigned in due time.

When observing the use of additional tools, 40 percent of respondents did not seem to need other supporting software or applications. From the remaining 60 percent, three-quarters suggested the adequacy of replacing Moodle message boards (in the cohorts where this tool was used) for IM applications. Alternative digital communication systems used by students include Discord, Skype, and WhatsApp. The remaining responses mention collaborative platforms for document sharing, such as Google Drive; Version Control Systems or Repl.it for code sharing; or Trello and Goodnotes for work organization purposes.

The opinion of the students about Telegram (in the cohorts where it was used) may be summarized in that they find that Telegram is a straightforward tool, simple but powerful enough, with the added benefit that it is compatible with their everyday life and accessible via mobile phones. Students also find positive aspects in bot-based group management and that they do not need to share their personal information.

\section{Conclusion}

Teamwork is a highly demanded competence by the labor market and has gained relevance in education. This makes it necessary to assess whether students acquire TWC during their academic education. Assessment of TWC may be performed by observing student interactions when they work in teams. The observation of these interactions may be biased when students communicate through spaces that do not feel natural to them; therefore, for real and natural interaction to occur it is worth considering whether the tools and devices students use are compatible with and integrated in their everyday life. Additionally, assessment of student interactions when working in teams is a time-consuming task, especially in classes with high number of students. This study included the results from the application of a learning analytics tool to facilitate assessment of individual TWC based on student interactions across two courses and two different communication systems (message boards and IM applications).

The main conclusions of the study are that: 1) it is possible to collect and analyze messages of students in IM applications, such as Telegram, as well as to design learning analytics tools with that purpose to facilitate instructors' monitoring and assessment of students; 2) students use and accept IM applications in a more natural way than other systems that have traditionally been in place for communication in learning environments, such as message boards; a benefit of IM applications is that they are multi-device applications that provide students with instant notifications and are more compatible with their lifestyles; 3) CTMTC is flexible enough to be directly applied or easily adapted to different educational contexts and tools; 4) student participation (as per number of messages) has improved with the introduction of Telegram in the courses, which might reflect higher involvement and engagement; 5) the results confirm the strong positive relationship between messages sent and individual TWC acquisition; and 6) the research finds contrarian evidence about the positive influence of IM apps use over message boards as team communication and discussion spaces [21]. The study discusses some of the reasons that could help explain this finding, including the effects of lockdown due to the COVID19 pandemic outbreak, but further research is required to address this issue. Future research should explore other potential educational applications of Telegram in the same courses, beyond the COVID19 context, as well as compare the effects of using different IM applications.

\section{REFERENCES}

[1] R. Colomo-Palacios, C. Casado-Lumbreras, P. Soto-Acosta, F. J. GarcíaPeñalvo, and E. Tovar-Caro, "Competence gaps in software personnel: A multi-organizational study," Computers in Human Behavior, vol. 29, pp. 456-461, March 2013 2013, doi: 10.1016/j.chb.2012.04.021.

[2] D. E. Leidner and S. L. Jarvenpaa, 265-291., "The use of information technology to enhance management school education: A theoretical view.", MIS quarterly, vol. 19, no. 3, pp. 265-291, 1995.

[3] D. R. Vogel, R. M. Davison, and R. H. Shroff, "Sociocultural learning: A perspective on GSS-enabled global education," Communications of the Association for Information Systems, vol. 7, no. 1, 2001.

[4] Á. Fidalgo-Blanco, M. L. Sein-Echaluce, F. J. García-Peñalvo, and M. Á. Conde, "Using Learning Analytics to improve teamwork assessment," Computers in Human Behavior, vol. 47, no. 0, pp. 149-156, 2015, doi: 10.1016/j.chb.2014.11.050.

[5] M. A. Rosen et al., "Tools for evaluating team performance in simulationbased training," Journal of emergencies, trauma, and shock, vol. 3, no. 4, pp. 353-359, Oct-Dec 2010, doi: 10.4103/0974-2700.70746.

[6] D. J. Dwyer, R. L. Oser, and E. Salas, "Event-Based Approach to Training (EBAT)," The International fournal of Aviation Psychology, vol. 8, no. 3, pp. 209-221, 1998, doi: 10.1207/s15327108ijap0803_3.

[7] N. E. Lane, E. Salas, T. Franz, and R. Oser, "Improving the Measurement of Team Performance: The TARGETs Methodology," Military Psychology, vol. 6, no. 1, pp. 47-61, 1994, doi: 10.1207/s15327876mp0601_3.

[8] D. Schwab, H. G. Heneman Iii, and T. A. DeCotiis, Behaviorally anchored rating scales: A review of the literature. 2006, pp. 549-562.

[9] A. Frankel, R. Gardner, L. Maynard, A. J. T. J. C. J. o. Q. Kelly, and P. Safety, "Using the communication and teamwork skills (CATS) assessment to measure health care team performance," vol. 33, no. 9, pp. 549-558, 2007.

[10] P. H. Hackbert, "Building Entrepreneurial Teamwork Competencies in Collaborative Learning via Peer Assessments," vol. 1, no. 12, pp. 39-52, 2004.

[11] I. d. l. Ríos-Carmenado, B. Figueroa-Rodríguez, and F. Gómez-Gajardo, "Methodological Proposal for Teamwork Evaluation in the Field of Project Management Training," Procedia - Social and Behavioral Sciences, vol. 46, pp. 1664-1672, 2012, doi: https://doi.org/10.1016/j.sbspro.2012.05.358.

[12] K. Tasa, S. Taggar, and G. H. Seijts, "The development of collective efficacy in teams: a multilevel and longitudinal perspective," fournal of Applied Psychology, vol. 92, no. 1, pp. 17-27, 2007.

[13] Á. Fidalgo-Blanco, D. Lerís, M. L. Sein-Echaluce, and F. J. García-Peñalvo, "Monitoring Indicators for CTMTC: Comprehensive Training Model 
of the Teamwork Competence in Engineering Domain," International fournal of Engineering Education (IFEE), vol. 31, no. 3, pp. 829-838, 2015.

[14] D. Lerís, Á. Fidalgo, and M. L. Sein-Echaluce, "A comprehensive training model of the teamwork competence," International fournal of Learning and Intellectual Capital, vol. 11, no. 1, pp. 1-19, 2014.

[15] F. J. García-Peñalvo, A. Corell, V. Abella-García, and M. Grande, "Online assessment in higher education in the time of COVID-19," Education in the Knowledge Society, vol. 21, Art no. 12, 2020, doi: 10.14201/eks.23013.

[16] F. J. García Peñalvo and A. Corell, "La COVID-19:; enzima de la transformación digital de la docencia o reflejo de una crisis metodológica y competencial en la educación superior?," Campus Virtuales, vol. 9, no. 2, pp. 83-98, 2020.

[17] C. Lewis and B. Fabos, "Instant messaging, literacies, and social identities," vol. 40, no. 4, pp. 470-501, 2005, doi: doi:10.1598/RRQ.40.4.5.

[18] D. Carnevale, "Email is for old people," The Chronicle of Higher Education, vol. 53, no. 7, 2006.

[19] R. Junco and J. Mastrodicasa, Connecting to the Net.generation: What Higher Education Professionals Need to Know about Today's Students. US: NASPA, National Association of Student Personnel Administrators, Student Affairs Administrators in Higher Education, 2007.

[20] Statista. "Most popular global mobile messenger apps as of October 2020, based on number of monthly active users." https://www.statista. com/statistics/258749/most-popular-global-mobile-messenger-apps/ (accessed 03/02/2020).

[21] M. Á. Conde, F. J. Rodríguez-Sedano, F. J. Rodríguez-Lera, A. GutiérrezFernández, and Á. M. Guerrero-Higueras, "Assessing the individual acquisition of teamwork competence by exploring students' instant messaging tools use: the WhatsApp case study," Univ Access Inf Soc, 2020/11/01 2020, doi: 10.1007/s10209-020-00772-1.

[22] M. Á. Conde, F. J. Rodríguez-Sedano, F. J. Rodríguez-Lera, A. GutiérrezFernández, and Á. M. Guerrero-Higueras, "Analyzing Students' WhatsApp Messages to Evaluate the Individual Acquisition of Teamwork Competence," in Learning and Collaboration Technologies. Ubiquitous and Virtual Environments for Learning and Collaboration. HCII 2019. Lecture Notes in Computer Science, Z. P. and I. A. Eds., (Learning and Collaboration Technologies. Ubiquitous and Virtual Environments for Learning and Collaboration, P. Zaphiris and A. Ioannou, Eds. Cham: Springer International Publishing, 2019, pp. 26-36.

[23] T. Sutikno, L. Handayani, D. Stiawan, M. A. Riyadi, and I. M. I. Subroto, "WhatsApp, viber and telegram: Which is the best for instant messaging?," International fournal of Electrical \& Computer Engineering (2088-8708), vol. 6, no. 3, 2016.

[24] M. Á. Conde, F. J. Rodríguez-Sedano, C. Fernández, A. GutiérrezFernández, L. Fernández-Robles, and M. C. Limas, "A Learning Analytics tool for the analysis of students' Telegram messages in the context of teamwork virtual activities," presented at the Eighth International Conference on Technological Ecosystems for Enhancing Multiculturality, Salamanca, Spain, 2020. [Online]. Available: 10.1145/3434780.3436601.

[25] M. Á. Conde, Á. Hernández-García, F. J. García-Peñalvo, Á. FidalgoBlanco, and M. Sein-Echaluce, "Evaluation of the CTMTC Methodology for Assessment of Teamwork Competence Development and Acquisition in Higher Education," in Learning and Collaboration Technologies: Third International Conference, LCT 2016, Held as Part of HCI International 2016, Toronto, ON, Canada, fuly 17-22, 2016, Proceedings, P. Zaphiris and A. Ioannou Eds. Cham: Springer International Publishing, 2016, pp. 201-212.

[26] J. L. Green, G. Camilli, and P. B. Elmore, Handbook of Complementary Methods in Education Research. American Educational Research Association by Lawrence Erlbaum Associates, Inc, 2006.

[27] AEIPRO-IPMA. "NCB.- Bases para la competencia en dirección de proyectos."http://www.lpzconsulting.com/images/CP_Trabajo_en_ Equipo.pdf (accessed 28/02/2014).

[28] A. Fidalgo, D. Leris, M. L. Sein-Echaluce, and F. J. García-Peñalvo, "Indicadores para el seguimiento de evaluación de la competencia de trabajo en equipo a través del método CTMT," presented at the Congreso Internacional sobre Aprendizaje Innovación y Competitividad - CINAIC 2013, Madrid, Spain, 2013.

[29] M. Á. Conde, F. J. Rodríguez-Sedano, L. Sánchez-González, C. FernándezLlamas, F. J. Rodríguez-Lera, and V. Matellán-Olivera, "Evaluation of teamwork competence acquisition by using CTMTC methodology and learning analytics techniques," presented at the Proceedings of the Fourth International Conference on Technological Ecosystems for Enhancing Multiculturality, Salamanca, Spain, 2016.
[30] M. L. Séin-Echaluce, Á. Fidalgo-Blanco, F. J. García-Peñalvo, and M. Á. Conde, "A Knowledge Management System to Classify Social Educational Resources Within a Subject Using Teamwork Techniques," in Learning and Collaboration Technologies: Second International Conference, LCT 2015, Held as Part of HCI International 2015, Los Angeles, CA, USA, August 2-7, 2015, Proceedings, P. Zaphiris and A. Ioannou Eds. Cham: Springer International Publishing, 2015, pp. 510-519.

[31] M. L. Sein-Echaluce, Á. Fidalgo-Blanco, and F. J. García-Peñalvo, "Students' Knowledge Sharing to improve Learning in Engineering Academic Courses.", International fournal of Engineering Education (IJEE), vol. 32, no. 2B, pp. 1024-1035, 2016.

[32] M. A. Conde, R. Colomo-Palacios, F. J. García-Peñalvo, and X. Larrucea, "Teamwork assessment in the educational web of data: A learning analytics approach towards ISO 10018," Telematics and Informatics, vol. 35, no. 3, pp. 551-563, 2018, doi: 10.1016/j.tele.2017.02.001.

[33] A. Álvarez-Arana, M. Larrañaga-Olagaray, and M. Villamañe-Gironés, "Mejora de los procesos de evaluación mediante analítica visual del aprendizaje," Education in the Knowledge Society, vol. 21, Art no. 9, 2020, doi: $10.14201 /$ eks. 21554

[34] A. Martínez-Monés et al., "Achievements and challenges in learning analytics in Spain: The view of SNOLA," Revista Iberoamericana de Educación a Distancia, vol. 23, no. 2, pp. 187-212, 2020, doi: 10.5944/ ried.23.2.26541.

[35] Ggstatsplot: "ggplot2" based plots with statistical details. (2018). Zenodo.

[36] M. B. Miles and A. M. Huberman, Qualitative Data Analysis: An Expanded Sourcebook. Sage Publications, 1994.

[37] M. Seufert, A. Schwind, T. Hoßfeld, and P. Tran-Gia, "Analysis of GroupBased Communication in WhatsApp," Cham, 2015: Springer International Publishing, in Mobile Networks and Management, pp. 225-238.

[38] A. Rosenfeld, S. Sina, D. Sarne, O. Avidov, and S. Kraus, "A study of WhatsApp usage patterns and prediction models without message content," arXiv preprint arXiv:1802.03393, 2018

[39] T. Iiyoshi, M. J. Hannafin, and F. Wang, "Cognitive tools and studentcentred learning: rethinking tools, functions and applications," Educational Media International, vol. 42, no. 4, pp. 281-296, 2005.

[40] Á. F. Agudo-Peregrina, S. Iglesias-Pradas, M. Á. Conde-González, and Á. Hernández-García, "Can we predict success from log data in VLEs? Classification of interactions for learning analytics and their relation with performance in VLE-supported F2F and online learning," Computers in Human Behavior, vol. 31, no. 0, pp. 542-550, 2// 2014, doi: 10.1016/j. chb.2013.05.031.

[41] C. M. Tavani and S. C. Losh, "Motivation, self-confidence, and expectations as predictors of the academic performances among our high school students," Child study journal, vol. 33, no. 3, pp. 141-152, 2003.

[42] A. Edman, F. Andersson, T. Kawnine, and C.-A. Soames, "Informal math coaching by instant messaging: Two case studies of how university students coach K-12 students AU - Hrastinski, Stefan," Interactive Learning Environments, vol. 22, no. 1, pp. 84-96, 2014/01/02 2014, doi: 10.1080/10494820.2011.641682.

[43] O. E. Cifuentes and N. H. Lents, "Increasing student-teacher interactions at an urban commuter campus through instant messaging and online office hours," Electronic fournal of Science Education, vol. 14, no. 1, 2010.

[44] I. Smit and R. Goede, "WhatsApp with BlackBerry; can messengers be MXit? A philosophical approach to evaluate social networking sites." [Online]. Available: https://repository.nwu.ac.za/handle/10394/13628

[45] S. M. Sweeny, "Writing for the instant messaging and text messaging generation: Using new literacies to support writing instruction," fournal of Adolescent \& Adult Literacy, vol. 54, no. 2, pp. 121-130, 2010.

[46] S. Lauricella and R. Kay, "Exploring the use of text and instant messaging in higher education classrooms," Research in Learning Technology, vol. 21, 2013.

[47] A. Z. Klein, J. C. d.-S.-F.-. Junior, J. V. Vieira-Mattiello-Mattiello-da-Silva, J. L. Victoria-Barbosa, and L. Baldasso, "The Educational Affordances of Mobile Instant Messaging MIM: Results of Whatsapp Used in Higher Education," International fournal of Distance Education Technologies, vol. 16, no. 2, pp. 51-64, 2018, doi: 10.4018/ijdet.2018040104.

[48] A. B. Fox, J. Rosen, and M. Crawford, "Distractions, Distractions: Does Instant Messaging Affect College Students' Performance on a Concurrent Reading Comprehension Task?”, vol. 12, no. 1, pp. 51-53, 2009, doi: 10.1089/cpb.2008.0107. 
[49] R. Junco and S. R. Cotten, "Perceived academic effects of instant messaging use," Computers \& Education, vol. 56, no. 2, pp. 370-378, 2011/02/01/ 2011, doi: 10.1016/j.compedu.2010.08.020.

[50] Alttop9. "6 Telegram Features that WhatsApp Does Not Have (Updated 2021)." https://cutt.ly/HkfvQaB (accessed 03/02/2021.

[51] MVWConsulting. "Telegram VS Signal, With WhatsApp Comparison Table.” https://meganvwalker.com/telegram-vs-signal-with-whatsappcomparison-table/ (accessed 03/02/2021).

[52] Y. Fernández. "Telegram vs WhatsApp: en qué se parecen y en qué se diferencian ambas aplicaciones." https://www.xataka.com/basics/ telegram-vs-whatsapp-en-que-se-parecen-y-en-que-se-diferencianambas-aplicaciones (accessed 03/02/2021).

[53] E. E. Gallardo-Echenique, L. Marqués-Molías, M. Bullen, and J.-W. Strijbos, "Let's talk about digital learners in the digital era," International Review of Research in Open and Distributed Learning, vol. 16, no. 3, pp. 156-187, 2015, doi: 10.19173/irrodl.v16i3.2196.

[54] T. Gonzalez et al., "Influence of COVID-19 confinement on students' performance in higher education," PLOS ONE, vol. 15, no. 10, p. e0239490, 2020, doi: 10.1371/journal.pone.0239490.

[55] S. Iglesias-Pradas, Á. Hernández-García, J. Chaparro-Peláez, and J. L. Prieto, "Emergency remote teaching and students' academic performance in higher education during the COVID-19 pandemic: A case study," Computers in Human Behavior, vol. 119, p. 106713, 2021/06/01 2021, doi: 10.1016/j.chb.2021.106713.

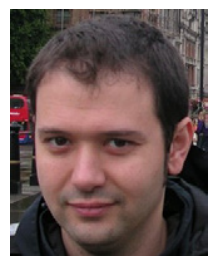

Miguel Á. Conde

Miguel Á Conde holds a PhD in Computer Science (2012, University of Salamanca). From 2002 to 2004 he was working in educational environment teaching in several courses related to computers. From 2004 he decided to begin working on software development and eLearning. From 2010 to 2012 he was researching at the University of Salamanca and also working there as a teacher. During 2013 he worked in the Informatics and Communications Service of the University of León and as assistant lecturer in that university. Now he works as an associate professor at the University of León. He is a member of the Robotics research group of the University of León and GRIAL research group of the University of Salamanca. His $\mathrm{PhD}$ thesis is focused on the merging of informal, non-formal and formal environments. He has published more than 150 papers about different topics such as eLearning, Service Oriented Architectures, Learning Analytics, Mobile Learning, Human-Computer Interaction, Educational Robotics, etc.

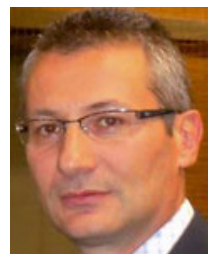

\section{Francisco J. Rodríguez-Sedano}

Dr. Francisco J. Rodríguez-Sedano received his Ph.D. degree in intelligent systems for engineering in 2010 from the School of Industrial Engineering and Information Technology at University of León (ULE). Professionally, in 1997 he joined the ULE and currently remains contractually linked to this University as associate professor. In 2014 he joined the Robotics Research Group of the University of León, where he is currently involved in several research projects in the field of social robotics and human-robot interaction. Much of his research interest are accessibility, educational innovation, graphical user interface design and evaluation, humancomputer interaction (HCI) and human-robot interaction (HRI).

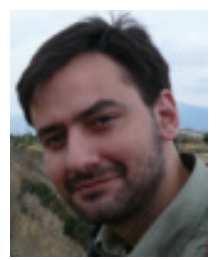

\section{Ángel Hernández-García}

is MSc in Telecommunication Engineering, Master SAP in Integrated Information Systems, and $\mathrm{PhD}$ in Information Systems by Universidad Politécnica de Madrid (Spain). He is Associate Professor at the Department of Organization Engineering, Business Administration and Statistics (School of Telecommunication Engineering, Universidad Politécnica de Madrid). He focuses his research on electronic commerce, technology acceptance, social media and learning analytics. He has been guest editor and published research articles in leading international journals.

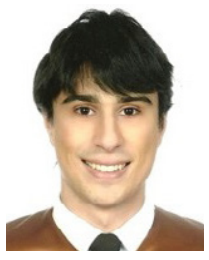

\section{Alexis Gutiérrez-Fernández}

Authors should include their biographies at the end of papers. A typical length for a biography is between 180 and 250 words. The biography can contain the author's educational background, academic and professional life and research expertise. The degrees should be listed indicating institution, country, and year. The photograph is placed at the top left of the biography. The authors can list their research interests. If personal hobbies are included, they will be deleted from the biography.

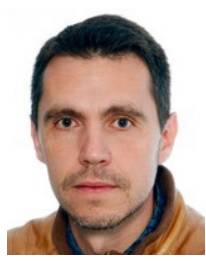

\section{Ángel M. Guerrero-Higueras}

Ángel Manuel Guerrero Higueras has worked as IT engineer at several companies in the private sector from 2000 to 2010 and 2014 to 2016. He also has worked as research assistant in the Atmospheric Physics Group at University of León from 2011 to 2013 and in the Research Institute of Applied Science to Cyber-Security at University of León from 2016 to 2018. He got his Ph.D. at the University of León in 2017. He currently works as Assistant Professor at University of León. His main research interests include robotic software architectures, cybersecurity, and learning algorithms applied to robotics. 